\title{
Retraction Note: Coastal environmental monitoring and port coal logistics optimization based on GIS remote sensing platform
}

\author{
Meixia Yang ${ }^{1}$
}

Published online: 23 November 2021

C) Saudi Society for Geosciences 2021

Retraction Note: Arabian Journal of Geosciences (2021) 14: 1161 https://doi.org/10.1007/s12517-021-07420-9

The Editor-in-Chief and the Publisher have retracted this article because the content of this article is nonsensical. The peer review process was not carried out in accordance with the Publisher's peer review policy. The author has not responded to correspondence regarding this retraction.

The original article can be found online at https://doi.org/10.1007/ s12517-021-07420-9.

Meixia Yang

yangmeixia8332@163.com

1 School of Business, Fuzhou Technology and Business

University, Yongtai 350700, China 